\title{
Perencanaan Perbaikan Tanah Dasar dan Perkuatan Stabilitas Timbunan Jalan Tol Pasuruan-Grati STA $30+100$ s.d STA $31+500$
}

\author{
Aditya Daniar Wicaksono, Noor Endah Mochtar, dan Putu Tantri Kumalasari \\ Departemen Teknik Sipil, Fakultas Teknik Sipil dan Perencanaan, Institut Teknologi Sepuluh \\ Nopember (ITS) \\ e-mail:noor_endah@ce.its.id
}

\begin{abstract}
Abstrak-Jalan tol Trans-Jawa merupakan salah satu infrastruktur transportasi yang direncanakan pemerintah untuk meningkatkan ekonomi negara dan mengembangkan wilayah serta meningkatkan mobilitas dan aksesibilitas. Jalan tol Pasuruan-Grati yang merupakan seksi III dari jalan tol Gempol-Pasuruan memiliki ketebalan tanah lempung lunak yang bervariasi dan pada beberapa lokasi memiliki ketebalan yang relative dalam. Oleh sebab itu, di lokasi tersebut perlu dilakukan perbaikan tanah dasar dan diberi perkuatan untuk meningkatkan stabilitas timbunannya. Pengumpulan data dilakukan untuk merencanakan perbaikan tanah dasar dan perkuatan stabilitas timbunan. Perencanaan yang ada akan menggunakan Preloading dan Prefabricated Vertical Drain (PVD) sebagai perbaikan tanah dasar. Sedangkan perkuatan stabilitas yang digunakan adalah Geotextile dan GeotextileEncased Stone Column (GESC). Dalam perencanaannya terdapat 5 titik Stationing (STA) yang akan ditinjau yaitu STA 30+100, STA 30+500, STA 31+000, STA 31+250, dan STA 31+500. Setiap STA yang ditinjau diwakili oleh tanah dasar yang berada disekitarnya. Prefabricated Vertical Drain (PVD) yang direncanakan menggunakan pola segitiga pada seluruh STA dan kedalaman bervariasi dengan menggunakan spesifikasi CT-D812. Geotextile yang digunakan memiliki spesifikasi UW-250 pada seluruh STA. Geosynthetics Encased Stone Column (GESC) direncanakan menggunakan Geotextile dengan spesifikasi UW-250 dan kolom batu pecah berdiameter 0,5 m untuk STA 30+100, STA 30+500, STA 31+250, dan STA $30+100$ serta kolom batu dengan diameter 0,8 untuk STA 31+000. Dari hasil perencanaan dan perhitungan biaya didapatkan alternatif yang paling optimum yaitu, pada STA 30+100 dipasang PVD sampai dengan 2/3 kedalaman tanah lunak tanpa menggunakan perkuatan stabilitas timbunannya. Untuk STA 30+500 dipasang PVD sampai dengan 1/3 kedalaman tanah lunak dan Geotextile sebagai perkuatan stabilitas timbunannya. Pada STA 31+000 dipasang PVD 2/3 kedalaman tanah lunak dan GESC untuk kestabilan timbunannya. Pada STA 31+250 dipasang PVD sampai dengan 1/3 kedalaman tanah lunak dan GESC sebagai perkuatan kestabilan timbunannya. Sedangkan untuk STA 31+500 dipasang PVD hingga 1/3 kedalaman tanah lunak dan perkuatan stabilitas timbunan berupa Geotextile.
\end{abstract}

Kata kunci-Perbaikan Tanah Dasar , Preloading, Prefabricated Vertical Drain (PVD), Geotextile-Encased Stone Column (GESC), Tol Pasuruan-Grati

\section{PENDAHULUAN}

$\mathrm{J}$ ALAN tol Pasuruan-Grati yang merupakan seksi III dari jalan tol Gempol-Pasuruan direncanakan akan dimulai pembangunannya pada awal tahun 2017. Dengan adanya jalan tol ini diharapkan akan memacu pertumbuhan ekonomi di sekitar kawasan yang dilaluinya. Bagi pemerintah daerah dan investor kehadiran jalan tol ini akan menjadi daya tarik untuk berinvestasi pada sektor industri manufaktur, properti, dan pariwisata pada koridor yang dilalui jalan tol ini. Lokasi jalan tol Pasuruan-Grati ditunjukkan pada Gambar 1 [1]. Berdasarkan data dari PT Transmarga Jatim Pasuruan jalan tol ini akan dibangun di atas timbunan yang memiliki ketinggian bervariasi, selain rencana tinggi timbunan yang bervariasi lokasi pembangunan jalan tol ini juga memiliki kedalaman tanah lempung lunak yang bervariasi dan pada beberapa lokasi memiliki kedalaman yang relative dalam.

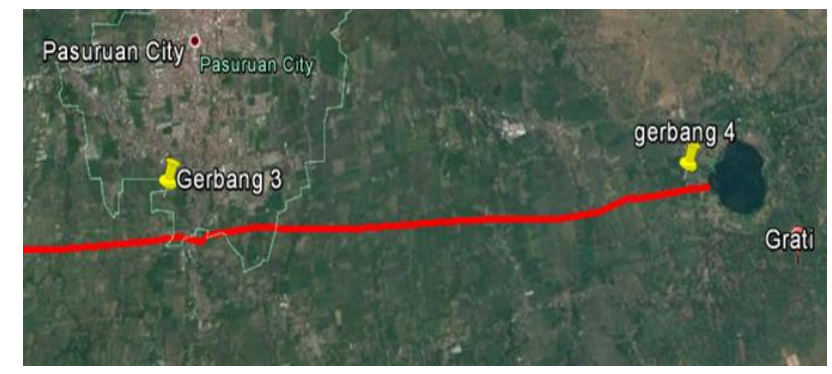

Gambar 1. Lokasi jalan tol Pasuruan-Grati.

Pada STA 30+100 s.d STA 31+500 diketahui memiliki kedalaman tanah mencapai 14 meter dan juga tinggi timbunan yang mencapai 10 meter (Gambar 2). Apabila suatu timbunan tinggi dibangun di atas tanah dasar yang relative lunak dan memiliki daya dukung yang rendah maka akan mempengaruhi kestabilan timbunan di atasnya. Ketidak stabilan timbunan yang dapat terjadi adalah berupa 
kelongsoran maupun kerusakan jalan (jalan menjadi bergelombang) akibat terjadinya differential settlement. Sehingga, perlu dilakukan perbaikan tanah dasar dan perkuatan stabilitas timbunan pada pembangunan jalan tol Pasuruan-Grati.

Perbaikan tanah dasar akan dilakukan menggunakan metode Prefabricated Vertical Drain (PVD) \& Preloading. Pada pemasangan PVD akan direncanakan menggunakan kedalaman yang bervariasi untuk mendapatkan panjang kedalaman PVD yang paling efektif. Pemampatan sisa yang terjadi setelah pemasangan PVD juga akan diperhitungkan, karena pada saat terjadi penerunan sisa diperlukan pemasangan overlay agar tinggi timbunan tetap seperti tinggi rencana. Sedangkan untuk perkuatan stabilitas timbunan akan dilakukan 2 alternatif, yaitu menggunakan Geotextile dan Geotextile-Encahased Stone Columns (GESC). Dari 2 alternatif ini akan dipilih dengan memperhatikan alternatif yang paling optimum dari segi biaya material. Oleh karena itu, pada Studi ini penulis akan merencanakan perbaikan tanah dasar dan perkuatan stabilitas timbunan pada jalan tol Pasuruan-Grati 30+100 s.d STA 31+500.

Dalam Studi ini hanya meninjau perbaikan tanah dasar dan juga perkuatan untuk stabilitas timbunan tidak meninjau metode konstruksi yang digunakan. Perkerasan jalan dan drainase jalan juga tidak menjadi bahasan pada Studi ini. Tujuan dari Studi ini adalah merencanakan alternatif perbaikan tanah dasar dan perencanaan stabilitas timbunan yang optimum dari segi biaya material. Studi ini diharapkan dapat menjadi referensi terhadap metode perbaikan tanah yang akan diterapkan pada proyek pembangunan jalan tol Pasuruan-Grati

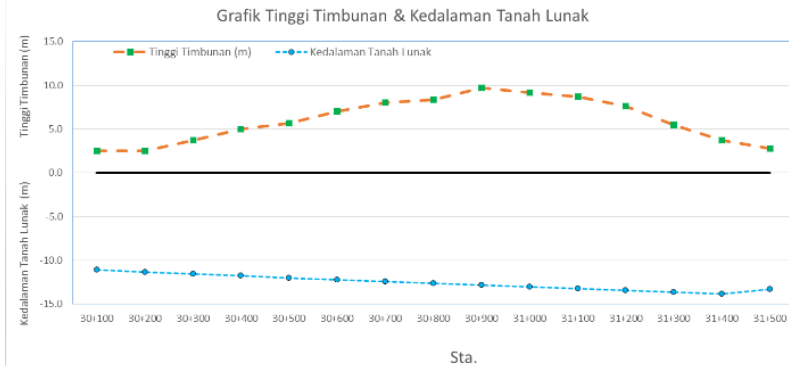

Gambar 2. Grafik tinggi timbunan dan kedalaman tanah lunak jalan tol Pasuruan-Grati

\section{METODOLOGI}

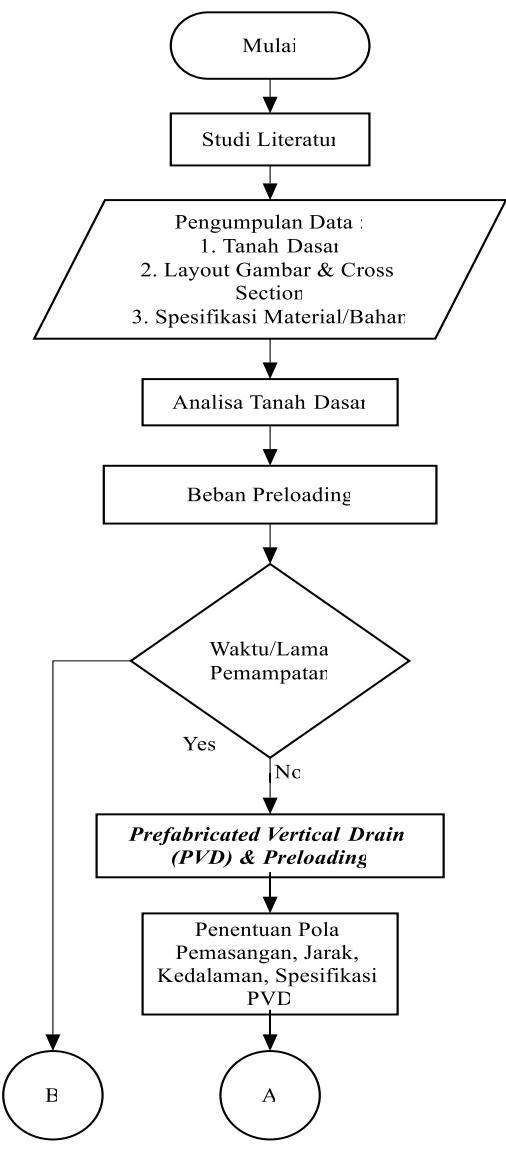




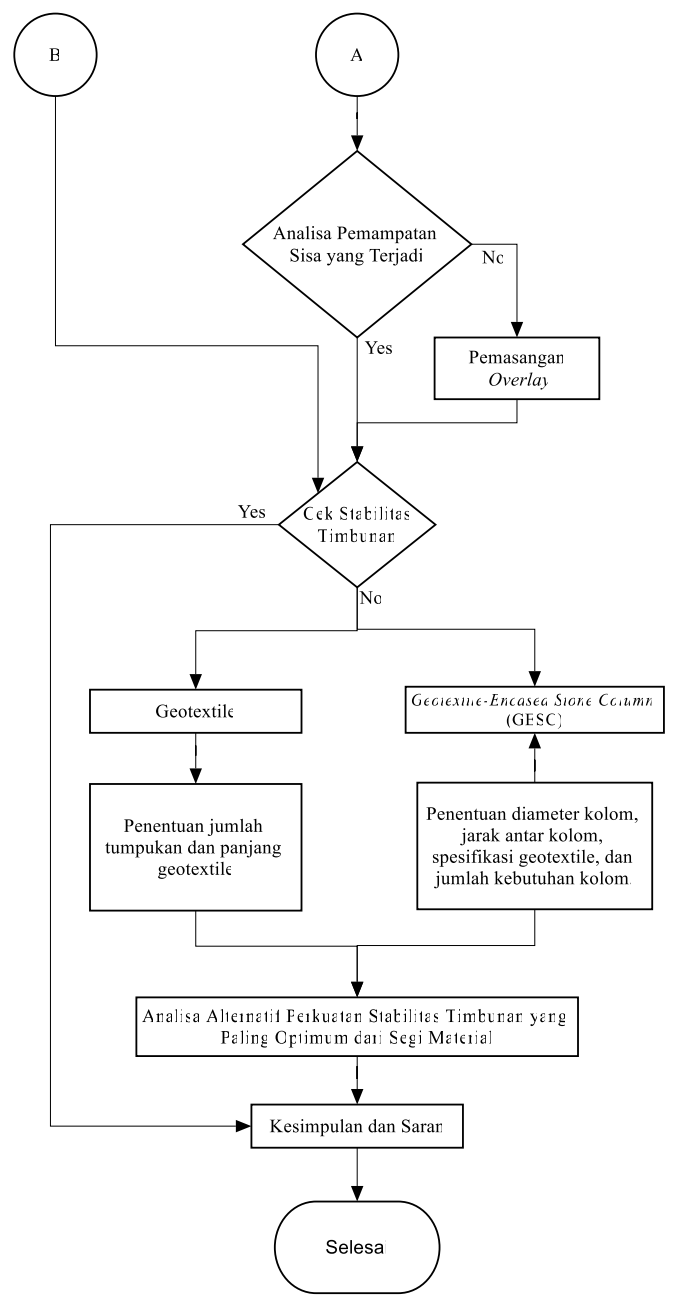

Gambar 3. Diagram Alir Studi

\section{HASIL DAN PEMBAHASAN}

\section{A. Analisis Data Perencanaan}

\section{Data Tanah}

Data tanah menggunakan data sekunder. Dari data tanah yang didapat hanya memiliki nilai N-SPT. Oleh karena itu untuk parameter lain dicari menggunakan statistik distribusi. Rekapitulasi data tanah dapat dilihat pada Tabel 1

Tabel 1

Rekapitulasi data tanah

$$
\text { STA } 30+100
$$

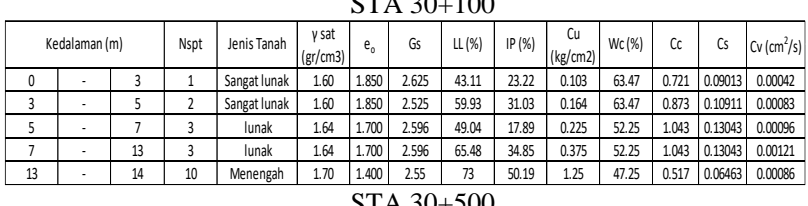
STA $30+500$

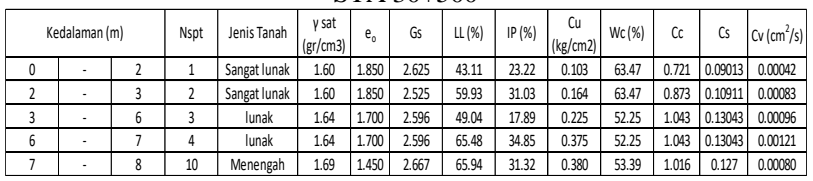

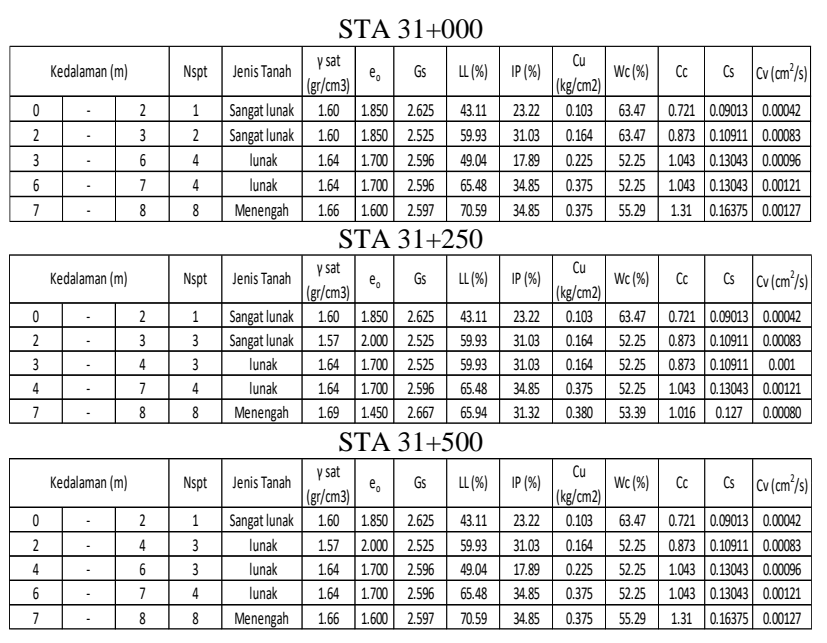

2. Spesifikasi Bahan

PVD menggunakan tipe CT-D812 dan Geotextile menggunakan tipe UW-250.

\section{B. Perhitungan Pemampatan (Sc), H inisial, dan Hfinal}

Besar pemampatan $(\mathrm{Sc})$ dihitung menggunakan rumus Terzaghi (1942) [2][3]. Perhitungan besar pemampatan dilakukan untuk mencari tinggi timbunan awal (Hinisial) yang dibutuhkan untuk mencapai tinggi rencana (Hfinal). Dalam Studi ini perencanaan Hinisial memperhitungkan beban timbunan, beban lalu lintas dan beban perkerasan. Rekapitulasi dari perhitungan Sc, Hinisial, dan Hfinal dapat dilihat pada Tabel 2.

Tabel 2

Rekapitulasi perhitungan Hinisial, Hfinal, dan Sc. (1)

\begin{tabular}{|c|c|c|c|c|c|}
\hline Variasi PVD & Kedal aman $(\mathrm{m})$ & Hinisial $(\mathrm{m})$ & H bongkar $(\mathrm{m})$ & $\mathrm{Sc}(\mathrm{m})$ & $H$ final (m) \\
\hline Seluruh Panjang Tanah Lunak & 14 & 6.0 & 1.45 & 2.10 & 2.5 \\
\hline 2/2 Tanah Lnak & 9 & 5.5 & 1.45 & 1.52 & 2.5 \\
\hline 1/3Tanah Lnnak & 5 & 4.8 & 1.45 & 0.88 & 2.5 \\
\hline
\end{tabular}

(2)

\begin{tabular}{|c|c|c|c|c|c|}
\hline Variasi PVD & Kedal aman $(\mathrm{m})$ & H inisial $(\mathrm{m})$ & $\mathrm{H}$ bongkar $(\mathrm{m})$ & $\mathrm{Sc}(\mathrm{m})$ & $\mathrm{H}$ final $(\mathrm{m})$ \\
\hline Seluruh Panjang Tanah Lunak & 8 & 8.4 & 0.69 & 1.97 & 5.7 \\
\hline 2/2Tanah Lunak & 5 & 7.7 & 0.69 & 1.27 & 5.7 \\
\hline 1/3Tanah Lunak & 3 & 7.1 & 0.69 & 0.74 & 5.7 \\
\hline
\end{tabular}

(3)

\begin{tabular}{|c|c|c|c|c|c|}
\hline Variasi PVD & Kedalaman $(\mathrm{m})$ & H inisial $(\mathrm{m})$ & H bongkar $(\mathrm{m})$ & $\mathrm{Sc}(\mathrm{m})$ & H final $(\mathrm{m})$ \\
\hline Seluruh Panjang Tanah Lunak & 8 & 123 & 0.69 & 2.38 & 9.2 \\
\hline 2/2Tanah Lunak & 5 & 114 & 0.69 & 149 & 9.2 \\
\hline 1/3Tanah Lunak & 3 & 10.7 & 0.69 & 0.83 & 9.2 \\
\hline
\end{tabular}

(4)

\begin{tabular}{|c|c|c|c|c|c|}
\hline Variasi PVD & Kedalaman $(\mathrm{m})$ & H inisial $(\mathrm{m})$ & H bongkar $(\mathrm{m})$ & $\mathrm{Sc}(\mathrm{m})$ & H final $(\mathrm{m})$ \\
\hline Seluruh Panjang Tanah Lunak & 8 & 9.2 & $0 . \oplus 9$ & 2.04 & 6.5 \\
\hline 2/2 Tanah Lunak & 5 & 8.5 & $0 . \oplus 9$ & 1.30 & 6.5 \\
\hline 1/3 Tanah Lunak & 3 & 8.0 & $0 . \oplus 9$ & 0.77 & 6.5 \\
\hline
\end{tabular}

(5)

\begin{tabular}{|c|c|c|c|c|c|}
\hline Variasi PVD & Kedalaman (m) & H inisial (m) & H bongkar (m) & Sc (m) & H final (m) \\
\hline Seluruh Panjang Tanah Lunak & 8 & 5.6 & 1.29 & 1.49 & 2.8 \\
\hline 2/2 Tanah Lunak & 5 & 5.0 & 1.29 & 0.94 & 2.8 \\
\hline $1 / 3$ Tanah Lunak & 3 & 4.7 & 1.29 & 0.57 & 2.8 \\
\hline
\end{tabular}




\section{Perencanaan Perbaikan Tanah}

Waktu yang diperlukan untuk menyelesaikan konsolidasi cukup lama disetiap STA, sehingga direncanakan perbaikan tanah menggunakan metode Preloading dan Prefabricated Vertical Drain (PVD) untuk mempercepat waktu konsolidasi. PVD yang digunakan akan menggunakan variasi kedalaman yang berbeda tiap STA diambil berdasarkan kedalaman optimum. Perbedaan PVD akan menghasilkan Hinisial dan besar pemampatan yang berbeda juga. Pemampatan terjadi akibat adanya beban timbunan yang akan dipasang bertahap. Berikut adalah besar nilai pemampatan yang terjadi akibat beban bertahap yang ditunjukan pada Tabel 3.

Tabel 3

Rekapitulasi pemampatan bertahap

\begin{tabular}{|c|c|c|}
\hline STA & Kedalaman PVD & Pemampatan bertahap $(\mathrm{m})$ \\
\hline \multirow{3}{*}{$30+100$} & Sepanjang tanah lunak & 2.13 \\
\cline { 2 - 3 } & $2 / 3$ tanah lunak & 1.54 \\
\cline { 2 - 3 } & $1 / 3$ tanah lunak & 0.86 \\
\hline \multirow{3}{*}{$30+500$} & Sepanjang tanah lunak & 1.86 \\
\cline { 2 - 3 } & $2 / 3$ tanah lunak & 1.18 \\
\cline { 2 - 3 } $31+000$ & $1 / 3$ tanah lunak & 0.59 \\
\hline \multirow{3}{*}{$31+250$} & Sepanjang tanah lunak & 2.21 \\
\cline { 2 - 3 } & $2 / 3$ tanah lunak & 1.35 \\
\cline { 2 - 3 } & $1 / 3$ tanah lunak & 0.75 \\
\cline { 2 - 3 } & Sepanjang tanah lunak & 1.89 \\
\cline { 2 - 3 } $31+500$ & $2 / 3$ tanah lunak & 1.18 \\
\hline \multirow{3}{*}{$31 / 3$ tanah lunak } & 0.70 \\
\cline { 2 - 3 } & Sepanjang tanah lunak & 1.44 \\
\cline { 2 - 3 } & $2 / 3$ tanah lunak & 0.91 \\
\cline { 2 - 3 } & $1 / 3$ tanah lunak & 0.54 \\
\hline
\end{tabular}

PVD yang digunakan dalam perencanaan adalah menggunakan pola segitiga dengan jarak antar PVD adalah 1,6 $\mathrm{m}$ dan 1,8 $\mathrm{m}$ dengan pertimbangan waktu tunggu 4-6 bulan dan kemudahan pelaksanaan pemasangan. Pemampatan sisa yang terjadi pada saat kedalaman PVD tidak penuh akan dihitung sebagai parameter jumlah kebutuhan overlay yang diperlukan di masa yang akan datang. Rekapitulasi perhitungan PVD dan kebutuhan Overlay disetiap STA dan seluruh variasi kedalaman PVD dapat dilihat pada Tabel 4.

Tabel 4

Rekapitulasi perhitungan PVD dan kebutuhan Overlay

\begin{tabular}{|c|c|c|c|c|c|c|}
\hline STA & \begin{tabular}{|c|}
$\begin{array}{c}\text { Kedalaman PVD } \\
(\mathrm{m})\end{array}$ \\
\end{tabular} & $\begin{array}{c}\text { Hinisial } \\
(\mathrm{m})\end{array}$ & $\begin{array}{l}\mathrm{H} \text { final } \\
(\mathrm{m})\end{array}$ & $\begin{array}{c}\text { Spasi } \\
\operatorname{PVD}(\mathrm{m})\end{array}$ & $\begin{array}{c}\text { Waktu PVD } \\
\text { (minggu) }\end{array}$ & $\begin{array}{c}\text { Kebutuhan Overlay } \\
(\mathrm{cm})\end{array}$ \\
\hline \multirow{3}{*}{$30+100$} & 14 & 6 & 2.5 & 1,6 & 18 & 0 \\
\hline & 9 & 5.5 & 2.5 & 1,6 & 18 & 51 \\
\hline & 5 & 4.8 & 2.5 & 1,6 & 17 & 104 \\
\hline \multirow{3}{*}{$30+500$} & 8 & 8.4 & 5.7 & 1,6 & 21 & 0 \\
\hline & 5 & 7.7 & 5.7 & 1,6 & 20 & 60 \\
\hline & 3 & 7.1 & 5.7 & 1,6 & 19 & 104 \\
\hline \multirow{3}{*}{$31+000$} & 8 & 12.3 & 9.2 & 1,8 & 21 & 0 \\
\hline & 5 & 11.4 & 9.2 & 1,8 & 20 & 81 \\
\hline & 3 & 10.7 & 9.2 & 1,8 & 18 & 134 \\
\hline \multirow{3}{*}{$31+250$} & 8 & 9.2 & $\begin{array}{ll}6.5 \\
\end{array}$ & 1,6 & 21 & 0 \\
\hline & 5 & 8.5 & $\begin{array}{l}6.5 \\
\end{array}$ & 1,6 & 20 & 63 \\
\hline & 3 & 8 & 6.5 & 1,6 & 19 & 107 \\
\hline \multirow{3}{*}{$31+500$} & 8 & 5.6 & 2.8 & 1,6 & 20 & 0 \\
\hline & 5 & 5 & 2.8 & 1,6 & 19 & 49 \\
\hline & 3 & 4.7 & 2.8 & 1,6 & 18 & 80 \\
\hline
\end{tabular}

\section{Perencanaan Perkuatan Stabilitas Timbunan}

Setelah menghitung perbaikan tanah menggunakan 3 variasi PVD akan dilakukan analisa dengan menggunakan progam bantu XSTABLE untuk mengetahui nilai Safety Factor (SF) pada setiap STA yang akan ditinjau. Nilai SF digunakan sebagai parameter untuk menghitung kebutuhan perkuatan stabilitas timbunan. Dalam perencanaan akan digunakan 2 alternatif metode yaitu:

\section{Geotextile}

Geotextile digunakan sebagai material perkuatan stabilitas timbunan untuk mencegah terjadinya longsor. Dari hasil analisis dengan menggunakan progam bantu XSTABLE akan didapatkan nilai Safety Factor (SF) dari masing-masing alternatif PVD setiap STA yang akan ditinjau, jika nilai dari $\mathrm{SF} \leq 1,5$ diperlukan penggunaan material geotextile untuk meningkatkan nilai SF. Perbedaan besarnya momen pada SF hasil analisa XSTABLE dengan SF yang direncanakan digunakan sebagai parameter untuk menentukan banyaknya jumlah geotextile yang diperlukan. Disetiap lapisan juga akan dihitung kebutuhan panjang geotextile minimal di depan bidang longsor $\left(\mathrm{L}_{\mathrm{d}}\right)$, di belakang bidang longsor $\left(\mathrm{L}_{\mathrm{e}}\right)$, serta panjang lipatan geotextile $\left(\mathrm{L}_{\circ}\right)$. Ilustrasi kebutuhan panjang geotextile dapat dilihat pada Gambar 4.

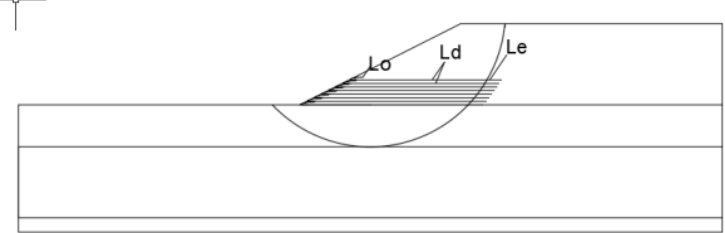

Gambar 4. Ilustrasi kebutuhan panjang geotextile

\section{Geotextile Encased Stone Column}

Dalam tanah yang sangat lembek dengan kekuatan gaya geser undrained yang rendah, kolom batu konvensional tidak dianjurkan karena batas tegangan efektif dari tanah tidak akan tercapai. Masalah penggunaan penggunaan kolom batu di tanah lunak tersebut dapat diselesaikan dengan membungkus kolom dengan perkuatan geotextile. Sistem ini diperkenalkan dengan nama Geotextile Encased Stone Columns (GESC) yang telah digunakan dan berhasil dalam praktek rekayasa dalam beberapa tahun terakhir [4].

Perencanaan geotextile encased stone column sebagai perkuatan stabilitas timbunan menggunakan perhitungan sama seperti stone column [5]. Jenis batu yang digunakan adalah batu pecah. Fungsi geotextile yaitu sebagai pembungkus agar mencegah stone column yang pada dasarnya tidak bisa dipakai untuk perkuatan stabilitas timbunan di tanah yang lunak supaya tidak merambat ke dalam tanah. Tegangan yang besar dari beban timbunan yang disalurkan ke stone column akan ditahan menggunakan geotextile untuk menjaga kekuatan dari stone column agar tidak merambat ke tanah. Jumlah stone column yang diperlukan akan dihitung berdasarkan kebutuhan momen penahan tambahan hingga memiliki nilai $\mathrm{SF} \geq 1,5$ yang merupakan angka keamanan terhadap bearing capacity failure. 
Rekapitulasi jumlah kebutuhan geotextile dan geotextile encased stone column disetiap STA dan seluruh variasi kedalaman PVD dipaparkan pada Tabel 5.

Tabel 5

Jumlah kebutuhan geotextile dan geotextile encased stone column

\begin{tabular}{|c|c|c|c|c|c|}
\hline STA & $\begin{array}{c}\text { Kedalaman PVD } \\
(\mathrm{m})\end{array}$ & $\begin{array}{c}\mathrm{H} \text { inisial } \\
(\mathrm{m})\end{array}$ & $\begin{array}{c}\mathrm{H} \text { final } \\
(\mathrm{m})\end{array}$ & $\begin{array}{c}\text { Geotextile } \\
(\text { lembar })\end{array}$ & $\begin{array}{c}\text { GESC } \\
\text { (jumlah) }\end{array}$ \\
\hline \multirow{3}{*}{$30+100$} & 14 & 6 & 2.5 & - & - \\
\cline { 2 - 6 } & 9 & 5.5 & 2.5 & - & - \\
\cline { 2 - 6 } & 5 & 4.8 & 2.5 & - & - \\
\hline \multirow{3}{3}{$30+500$} & 8 & 8.4 & 5.7 & 8 & 10 \\
\cline { 2 - 6 } & 5 & 7.7 & 5.7 & 12 & 12 \\
\cline { 2 - 6 } & 3 & 7.1 & 5.7 & 17 & 14 \\
\hline \multirow{3}{3}{$31+000$} & 8 & 12.3 & 9.2 & 37 & 8 \\
\cline { 2 - 6 } & 5 & 11.4 & 9.2 & 42 & 8 \\
\cline { 2 - 6 } $31+250$ & 3 & 10.7 & 9.2 & 46 & 8 \\
\cline { 2 - 6 } & 8 & 9.2 & 6.5 & 23 & 12 \\
\cline { 2 - 6 } & 5 & 8.5 & 6.5 & 13 & 8 \\
\hline \multirow{3}{3}{$31+500$} & 3 & 8 & 6.5 & 16 & 8 \\
\cline { 2 - 6 } & 8 & 5.6 & 2.8 & 3 & 6 \\
\cline { 2 - 6 } & 5 & 5 & 2.8 & 7 & 10 \\
\hline
\end{tabular}

E. Pemilihan Alternatif berdasarkan biaya material

Pemilihan alternatif dari perencanaan perbaikan tanah dasar dan stabilitas timbunan dari segi biaya material.

1. Biaya perbaikan tanah dasar meliputi :

- Biaya material Prefabricated Vertical Drain (PVD).

- Biaya material Prefabricated Horizontal Drain (PHD)

- Harga Timbunan

- Harga Overlay

2. Biaya perkuatan stabilitas timbunan meliputi:

- Biaya meterial Geotextile

- Biaya material Geotextile Encased Stone Column

Variasi alternatif berdasarkan perbaikan tanah dan perkuatan stabilitas timbunannya dapat dilihat pada Tabel 6 .

Tabel 6

Variasi Alternatif

\begin{tabular}{|cc|}
\hline ALTERNATIF 1 & PVD PENUH \& GEOTEXTILE \\
ALTERNATIF 2 & PVD 2/3 Hdr \& GEOTEXTILE \\
ALTERNATIF 3 & PVD $1 / 3$ Hdr \& GEOTEXTILE \\
ALTERNATIF 4 & PVD PENUH \& GESC \\
ALTERNATIF 5 & PVD 2/3 Hdr \& GESC \\
ALTERNATIF 6 & PVD 1/3 Hdr \& GESC \\
\hline
\end{tabular}

Hasil biaya perencanaan alternatif yang paling optimum dari segi material dapat dilihat pada Tabel 7.
Tabel 7

Total biaya alternatif yang terpilih

\begin{tabular}{|c|c|c|c|c|}
\hline STA & Alternatif yang dipilih & Biaya Perbaikan & $\begin{array}{c}\text { Biaya Perkuatan } \\
\text { Stabilitas }\end{array}$ & Total Biaya \\
\hline $30+100$ & ALTERNATIF 2 & Rp6.146.685.978 & - & Rp6.146.685.978 \\
\hline $30+500$ & ALTERNATIF 2 & Rp29.344.909.306 & Rp1.043.800.000 & Rp30.388.709.306 \\
\hline $31+000$ & ALTERNATIF 5 & Rp23.466,166.490 & Rp3.813.285.872 & Rp27.279.452.362 \\
\hline $31+250$ & ALTERNATIF 6 & Rp16.318,580.947 & Rp654.634.710 & Rp16.973.215.656 \\
\hline $31+500$ & ALTERNATIF 3 & Rp9.073,653.176 & Rp399.477.199 & Rp9.473.130.375 \\
\hline
\end{tabular}

\section{KESIMPULAN}

Dari hasil perencanaan dan anlisa yang telah dilakukan didapatkan alternatif yang teroptimum berdasarkan biaya material yang digunakan dari setiap STA. Pada STA 30+100 dipasang PVD sampai dengan $2 / 3$ kedalaman tanah lunak tanpa menggunakan perkuatan stabilitas timbunannya. Untuk STA 30+500 dipasang PVD sampai dengan 1/3 kedalaman tanah lunak dan Geotextile sebagai perkuatan stabilitas timbunannya. Pada STA $31+000$ dipasang PVD 2/3 kedalaman tanah lunak dan GESC untuk kestabilan timbunannya. Pada STA 31+250 dipasang PVD sampai dengan 1/3 kedalaman tanah lunak dan GESC sebagai perkuatan kestabilan timbunannya. Sedangkan untuk STA 31+500 dipasang PVD hingga 1/3 kedalaman tanah lunak dan perkuatan stabilitas timbunan berupa Geotextile. Biaya perbaikan tanah sendiri berbanding terbalik dengan biaya perkuatan tanah. Semakin murah biaya perbaikan tanah, maka semakin mahal biaya perkuatannya begitu juga sebaliknya.

\section{DAFTAR PUSTAKA}

[1] Andi, "DPRD minta Pembangunan tol Gempol Pasuruan Diperecepat," Kompas, 2016.

[2] N. E. Mochtar, "Modul Ajar Metode Perbaikan Tanah," Jur. Tek. Sipil, 2012.

[3] I. Mochtar. B, Teknologi Perbaikan Tanah dan Alternatif Pada Tanah Bermasalah (Problematic Soils). 2000.

[4] L. S. Alexiew D., Brokemper D., Geotextile Encased Columns (GEC):Load Capacity, Geotextile Selection and Pre-Design Graphs. 2005.

[5] F. H. A. U.S. Department of Transportation, DESIGN AND CONSTRUCTION OF STONE COLUMNS VOL. 1. TurnerFairbank Highway Research Center 6300 Georgetown Pike Mclean. Virginia, 1983. 